\title{
THE DPC PROCESS: A NEW CLEAN, EFFICIENT
} CARBONIZATION PROCESS*

Álvaro Lúcio'

Sidney Pessoa Vieira ${ }^{2}$

\begin{abstract}
This paper outlines the DPC process as na economic and environment friendly option for the use of cultivated forest as a source of raw material for metallurgical charcoal.The DPC process was specially developed to bring logistic, environmental, technical, economic and global energy efficiency when compared to termal 1 the existing biomass carbonization process. The DPC process utilizes the volatile materials (condensable and non condensable) as a source of the energy required by the carbonization process guarantying its complete combustion. As result the DPC process avoids the burning of termal1 the loaded wood, obtaining a higher charcoal to biomass yield, and avoids the emission to the atmosphere of polluting gases. Gases emitted by the carbonizing wood have na energy termal1e enough to dry the wood soon after its harvesting. By avoiding the storage in the field during na average of 150 days, the resulting economy is quite significant. As a termal1e1 the higher charcoal to biomass yield na termal1e1e economy is obtained through the reduction of the cultivated forest term. This paper emphasizes the economic advantages of the DPC process.
\end{abstract}

Keywords: Charcoal; Wood carbonization. 


\section{INTRODUCTION}

Brazil is the greatest charcoal producer in the world and almost $95 \%$ of its production occurs in the South East states of Minas Gerais, São Paulo, Goias and Bahia located approximately 3,000 miles frm the Amazon region. The charcoal main applications are: as termal-reducer I the iron, ferrous alloys, termal2e metal, calcium carbide furnaces and as renewable energy source in the calcining and cement industry. Approximately one third of the pig iron produced in Brazil is based on the use of charcoal as a termal-reducer.

\section{THE BASIC PRINCIPLES OF CHARCOAL MAKING}

Charcoal: the first wood product used by mankind. Cave men observed that the residue of burned wood produced a hotter flame with less smoke in the cave. Later on, when accidentally a mixture of this residue was fired together with certain types of stones, a heavy and hot liquid emerged, starting in that way the age of metals.

Pyrolysis or carbonization of wood is a complex process in which word components at temperatures up to $280-350^{\circ} \mathrm{C}$ in the absence of air are decomposed into vapors of volatile products, no condensable gases, and a solid product - charcoal - is formed. Three terms are used to describe this process depending on the desired final product:

Carbonization - Final product: charcoal.

Distillation - Final product: pyrolygneous liquor.

Gasification - Final product: gas

Carbonization of is performed in three steps:

Drying - Before word cold carbonized, the water in it must be driven off. Drying is the main endothermic period of wood carbonization.

Pyrolysis - It is a term loosely applied the chemical structure of wood breaks down under high temperature and in the absence of air. After starting the pyrolysis phase is exothermic and the temperature rises up to $350-380^{\circ} \mathrm{C}$ with the emission of hydrocarbon gaseous products, the solid residue becomes charcoal. The emitted gases during pyrolysis have a significant heating value. Gases species are: Co, Co2, $\mathrm{H} 2, \mathrm{CH} 4$, water vapor, hydrocarbon gases, and vapors of tar, methanol, acetic acid and pyrolygneos liquor (wood vinegar).

Cooling - The charcoal produced should be cooled, in order not to burn when opining the kiln or retort which must be tightly sealed.

\section{PROCESSES FOR CHARCOAL MANUFACTURE}

Charcoal can be made in many different ways. They can be divided into two broad categories:

Kiln methods, in which the necessary heat to maintain the processes is supplied by burning part of the charge of wood being turned into charcoal, and.

Retort process, in which the wood is converted into charcoal inside a closed vessel, usually a tall tower, with the necessary heat being supplied by an external source. The tower reactor for wood carbonization requires wood in small lengths, 15 to $25 \mathrm{~cm}$, whereas log wood up to 5 meters long has been carbonized in brick kilns.

Both processes - retort and brick kiln - limit the moisture content of the wood to a maximum of $35 \%$ (wet basis). soon after being cut, the wood contains an average of $50 \%$ (wet basis) of moisture. The wood must be properly stored in the air during a 
time of 90 to 120 days (dry and wet seasons in Brasil) in order to reduce the moisture from 50 to $30 \%$,which requires a financial cost of 120 days between crop and carbonization.

In Brasil only the brick kiln method used for charcoal making, which has the following disadvantages:

-Burning of part of the wood to supply heat for the process reducing its charcoal yield and energy efficiency.

-Loss of part of the energy and materials that are present in the volatile matter (wood tar and wood vinegar plus non condensable gases) and higher $\mathrm{CO}_{2}$ emissions that would be the case if those materials where used in benefit of the process.

- It is a labor intensive activity.

-Long time for the carbonization process from 8 to 12 days, depending on the kiln size ending up with low productivity.

-Waste of the gaseous combustible constituents (condensable and non condensable) emitted during the process.

$\mathrm{V} \& \mathrm{M}$ do Brasil is the only company that recovers the volatile materials while doing carbonization in Missouri type brick kilns. It also uses significant mechanical devices to reduce labor force and increase productivity. Anyway this is still far from the best that can be obtained by processes such as a DPC reactor.

\section{THE DPC PROCESS}

The basic concepts of the DPC process are:

1 - Utilization of the emitted gases - condensable and nom condensable - as a source of the thermal energy required by the carbonization process.

2 - Utilization of gases emitted during the pyrolysis step as a heat carrier for the endothermic stage of the pyrolysis.

3 - The functions of wood drying, pyrolysis and the charcoal are performed simultaneous and independently into at least three reactors, Figure 1. The emitted gases during pyrolysis with a significant heating value are burned in a combustion chamber, generating hot gases which are transported to the reactor performing the wood drying.

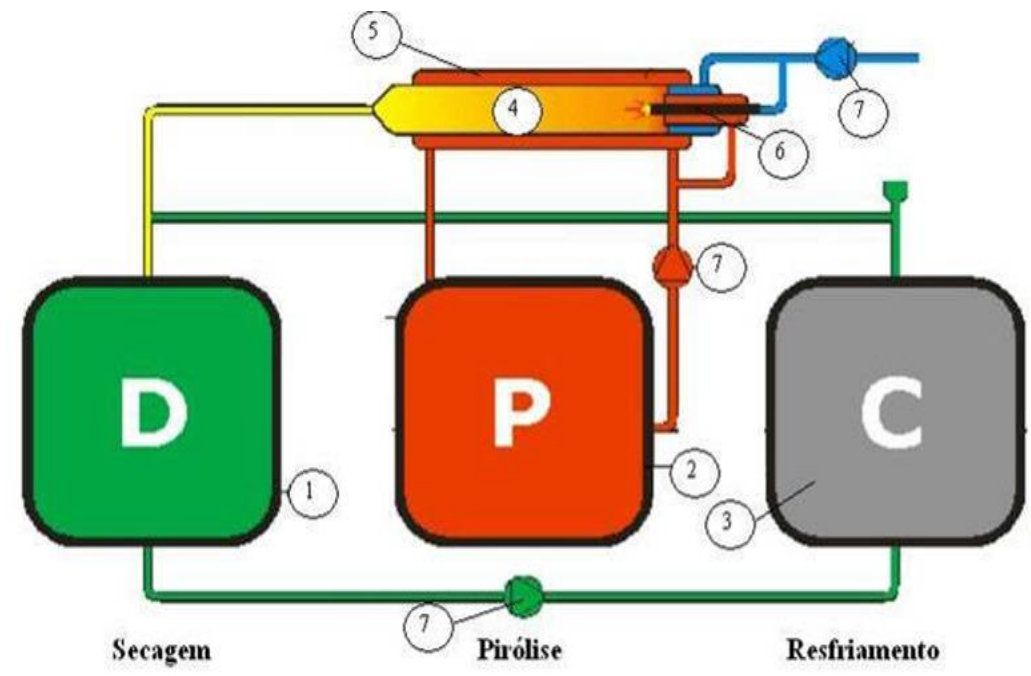

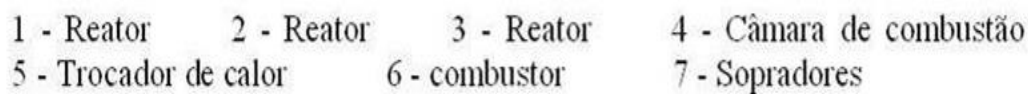

Figure 2 shows the DPC concepts applied to ten reactors. 
Any DPC reactor can perform the functions of drying, pyrolisis and cooling. Processes can be performed in more than three reactors, depending on the desired capacity of the charcoal plant.

When applying the DPC process for charcoal making, wood logs of up to 5 meters long can be loaded into the reactors; and the emitted volatile materials (hydrocarbon gases) are used as the heat source ande heat transfer media for the process. There is no wood burning, which increases the charcoal yield, that is the (kg of charcoal)/(ton of dried wood) ratio.

Furnaces for wood carbonization available until today require wood with maximum $35 \%$ humidity (wet basis) to avoid excessive yield losses. When the tree is harvested its wood carbonization have enough heating content to dry wood with $50 \%$ humidity. Therefore, there is no limitation to the wood humidity to be carbonized in DPC syste.

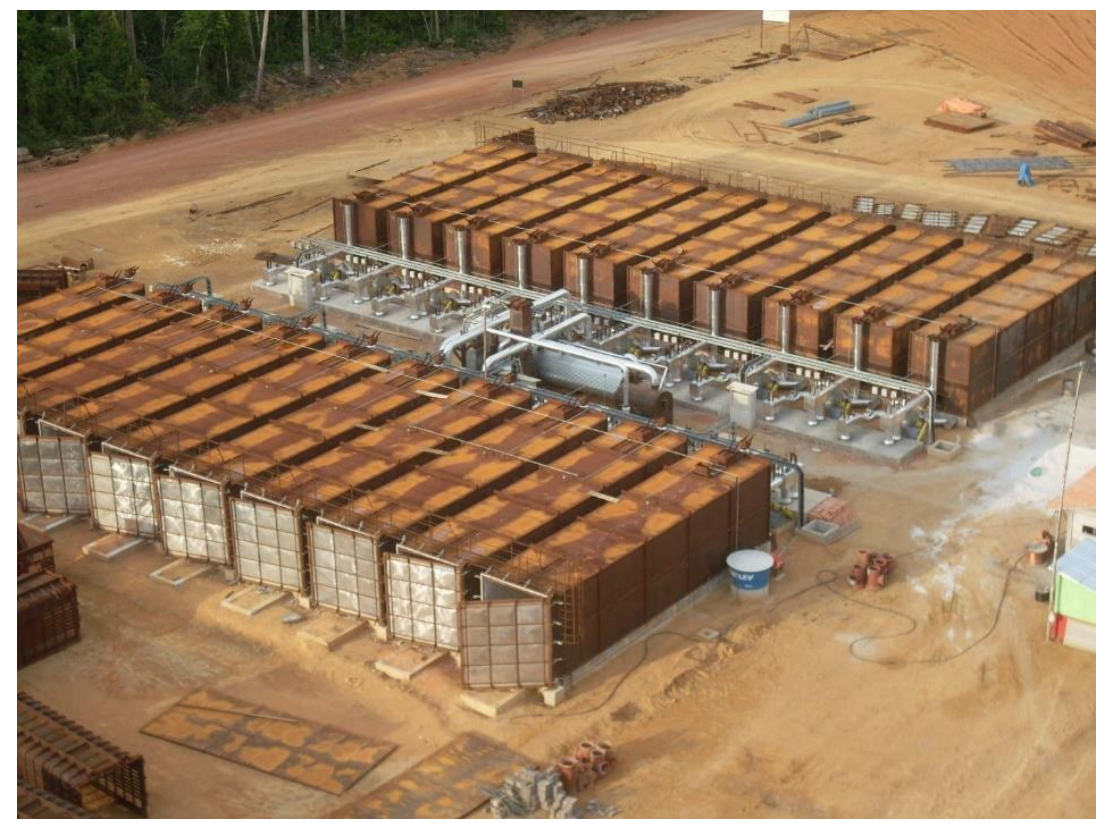

Figure 2 - Schematic view of a series of carbonization kilns using DPC process.

In the DPC process charcoal can be made from virtually any material. Wood, straw, coconut shells, bones, babassu, palm coconut,

Elephant grass and a variety of other biomass can be used.

The system is suitable to any degree of mechanization and automation. In a recent development wood and/or elephant grass is placed into the bucket of a roll on truck type container. The truck transports the biomass, and places the bucket into the rector. Finished the process the roll on container is removed and its content transferred to a charcoal bin.

The system has been improved by placing the combustion chamber and the heat exchanger into each reactor making it a completely independent init. The result is a significant reduction in the length and number of pipes and valves..

The process can be interrupted after the drying period in order to produce "bone dry wood", a very attractive biomass fuel. The process is suitable for the carbonization of elephant grass or other high productivity biomass crops, raising a new window of opportunities for the strong agricultural sector of the Brasilian economy. The production of dried tons of biomass from elephant grass is, per hectare a year, 3 times higher than a high productivity eucalyptus forest. In Brasil elephant grass can be harvested 4 times per year. 
Any small farmer, with low investment, can cultivate elephant grass. Harvesting elephant grass for energy applications can be an important job generator in remote and poor areas of our country.

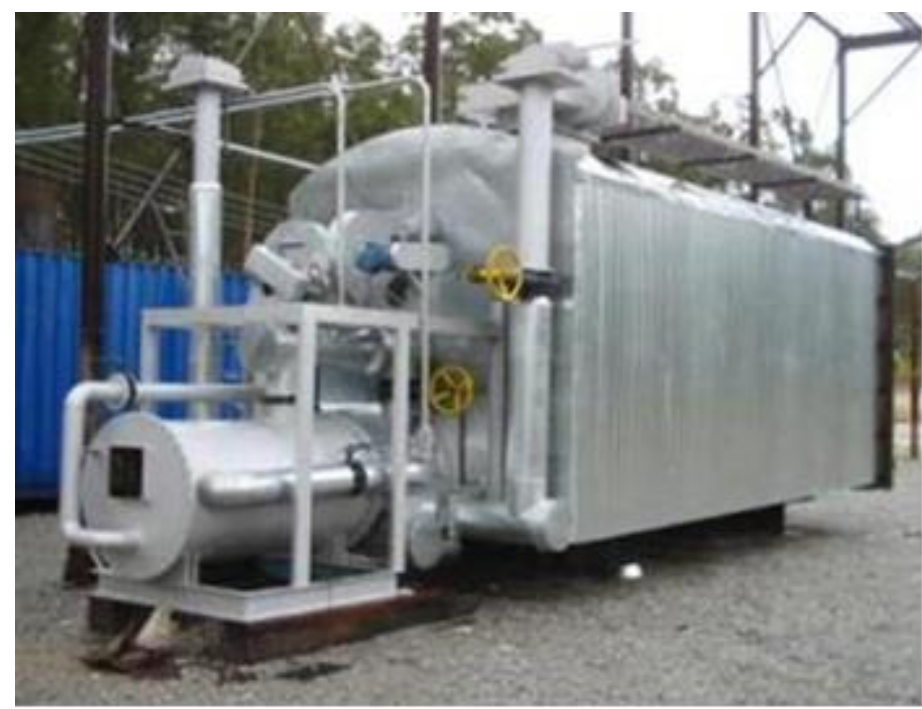

Figure 3 - A DPC reactor being fed with grass to produce charcoal for ironmaking and energy applications.

In should be mentioned that fossil fuels are not inexhaustible. Cultivate biomass is a permanent source of renewable energy.

The main advantages of the DPC process are:

1 - No noxious emissions to the atmosphere.

2 - It is not necessary to saw the wood in small lengths.

3 - It is not necessary to store the wood during a long time in order to reduce its humidity.

4 -lower labor cost.

5 -Higher charcoal yield.

6 - Able to produce dry bone word, a very convenient fuel.

7 - A lower charcoal production cost.

8 - It is a high productivity process, the residence time of the wet wood in the reactor is in the order of 60 hours.

9 - The investment cost expressed in US\$ per ton of charcoal is lower than the retort process (Continuous carbonization processes).

\section{DPC ECONOMIC ANALASYSIS}

We will consider in this analysis only the great advantage of the DPC process about the capability of carbonizing the wood soon after being harvested. We will not take into account DPC smaller operation cost.

Let us consider a pig iron plant capacity $50,000 \mathrm{t} / \mathrm{mo}$. Charcoal consumption: 150,000 charcoal cubic meters per month, that is 1.8 million per year.

\subsection{Charcoal Production from Large Brick Rectangular Kilns}

Wood consumption: $1.8 \times(2.1$ steres) equals 3.78 millions of esters per year. Time between cutting and loading the wood into the kiln: 5 months. 
Let us assume $R \$ 50.000$ per stere as the cost of cutting the wood, and the loading into the kiln five months later.

Floating capital: (3.78 millions steres/ year) x 50x5/12 equals $\mathrm{R} \$ 78.850$ millions.

\subsection{DPC Wood Carbonizing Plant.}

Wood consumption: $1.8 x$ ( 1.55 steres) equals 2.79 millions stress per year.

Time between cutting and loading the wood into the DPC reactor: maximum one month.

Floating capital: 2.79 millions steres/ year) $\times 50 \times 1 / 12$ equals $\mathrm{R} \$ 11.65$ millions.

Annual saving when comparing the DPC processes with the rectangular large brick kiln:

$\mathrm{R} \$ 78.750$ millions - $\mathrm{R} \$ 11.645$ millions equals $\mathrm{R} \$ 67.125$ millions almost US\$ 22,500 millions per year.

\section{3 - Cultivated Forest}

Large brick rectangular kilns: (3.78 millions st /year)x (50 st/ hectare. year) $/ 0.7$ equals 108.000 hectares total area. Capital investment: (US $\$ 4,200 /$ hectare)x108.000 $=$ US $\$ 453,000.00$.

DPC wood carbonizing plant: US $\$ 334,800,000.00$ capital investment.

Capital investmente saving when comparing the DPC process with the large rectangular brick kiln: US $\$ 334,800.00$ equals US $\$ 118.8$ millions.

\section{CONCLUSIONS}

a) The DPC Wood Carbonizing Process does not Pollute the Environment;

b) By not burning part of loaded wood the yield ( $\mathrm{kg}$ of charcoal)/ (ton of anhydrous wood) is than the large brick carbonizing klns;

c) Floating capital saving when comparing the DPC process with the large rectangular brick kil: US $\$ 22,500.00$;

d) Capital investment saving in the cultivated forest when comparing the DPC process with the large brick rectangular kiln: US $\$ 118,8000.00$.

\section{BIBLIOGRAPHY}

1 Lucio, A, Sampaio R. S Turning Biomass Into Metallurgical Charcoal Through A New Clean Carbonization Process, ABM 1 International Symposium On Iron Ore,September 12 to 15 , vitoria - Espírito Santo. 